\title{
ADAMTS13 ameliorates inflammatory responses in experimental autoimmune encephalomyelitis
}

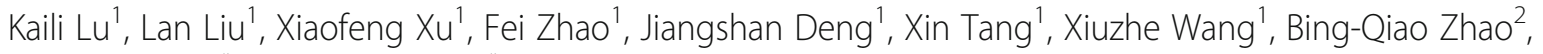
Xiaojie Zhang ${ }^{1 *}$ and Yuwu Zhao ${ }^{1 *}$

\begin{abstract}
Background: ADAMTS13 (a disintegrin and metalloprotease with a thrombospondin type 1 motif, member 13) plays a vital role in preventing microvascular thrombosis and inflammation. Reduced ADAMTS13 levels in plasma have been detected in multiple sclerosis (MS) patients. In the present study, we have determined the role of ADAMTS13 in the disease progression of MS using a mouse model of experimental autoimmune encephalomyelitis (EAE).

Methods: Female C57BL/6 mice were immunized with MOG $_{35-55}$ peptide and then treated with ADAMTS13 or vehicle in preventive and therapeutic settings. Mice were analyzed for clinical deficit, white matter demyelination and inflammatory cell infiltration. To explore the underlying mechanism, WWF expression and blood-spinal cord barriers (BSCB) were determined.

Results: Plasma ADAMTS13 activity was suppressed in EAE mice. ADAMTS13-treated EAE mice exhibited an ameliorated disease course, reduced demyelination, and decreased T lymphocyte, neutrophil and monocyte infiltration into the spinal cord. Consistently, ADAMTS13 treatment reduced WWF levels and inhibited BSCB breakdown in the spinal cords of EAE mice. However, leukocytes in the blood and spleen of EAE mice remained unaffected by ADAMTS13 administration.

Conclusion: Our results demonstrate that ADAMTS13 treatment ameliorates inflammatory responses, demyelination and disease course in EAE mice. Therefore, our study suggests that ADAMTS13 may represent a potential therapeutic strategy for MS patients.
\end{abstract}

Keywords: Multiple sclerosis, Experimental autoimmune encephalomyelitis, ADAMTS13, WWF, Inflammation

\section{Introduction}

Multiple sclerosis (MS) is an inflammatory demyelinating disease of the central nervous system (CNS), that is characterized by leukocyte infiltration and myelin damage $[1,2]$. As an animal model for MS, experimental autoimmune encephalomyelitis (EAE) has been widely used to study the pathophysiology and therapy of MS. It is commonly acknowledged that MS and EAE are mediated by autoreactive $\mathrm{T}$ lymphocyte cells that enter the CNS and initiate a chronic autoimmune response [3].

\footnotetext{
*Correspondence: xjzzhang@126.com; zhaoyuwu2005@126.com ${ }^{1}$ Department of Neurology, Shanghai Jiao Tong University Affiliated Sixth People's Hospital, No. 600, Yishan Road, Xuhui District, Shanghai, China Full list of author information is available at the end of the article
}

Recent years have seen an increasing relationship between hemostasis and inflammation. Cells and proteins of the hemostatic system, traditionally studied in thrombotic diseases, clearly play unexpected roles in MS and EAE. For example, tissue factor and protein $\mathrm{C}$ inhibitor were detected within the chronic active lesions MS patients by proteomic analysis [4]. In addition, thrombin and fibrinogen $[5,6]$ proteins were shown to promote CNS inflammation in MS. In addition, coagulation factor XII deficiency [7] and anticoagulation treatment with warfarin or rivaroxaban [8] were reported to ameliorate EAE injury by modulating inflammatory responses.

Interestingly, a recent study assessed plasma samples from MS patients and matched healthy individuals $(\mathrm{HI})$

(c) The Author(s). 2020 Open Access This article is distributed under the terms of the Creative Commons Attribution 4.0 International License (http://creativecommons.org/licenses/by/4.0/), which permits unrestricted use, distribution, and 
by magnetic Luminex assays and enzyme-linked immunosorbent assay (ELISA). Among the plasma hemostasis factors, ADAMTS13 levels were significantly decreased in MS patients [9]. ADAMTS13, a metalloprotease that is able to cleave von Willebrand factor (VWF), was first discovered in thrombotic thrombocytopenic purpura (TTP) [10, 11]. In addition, preclinical studies of ADAMTS13 have shown promise in reducing the inflammatory response of various neurological disease models such as ischemic and hemorrhagic stroke [1216]. Thus we were inspired to assess the potential influence of ADAMTS13 therapy on autoimmune inflammation in chronic EAE mice.

\section{Methods}

\section{Animals}

C57BL/6 female mice $(18-20 \mathrm{~g})$ were obtained from Shanghai Sipper-BK Laboratory Animal Corp. Ltd. Mice were bred and kept with a $12 \mathrm{~h}$ light-dark cycle, with free access to food and water under specific pathogenfree conditions. The study was approved by the Shanghai Jiao Tong University Affiliated Sixth People's Hospital Animal Ethics committee.

\section{EAE induction and scoring}

Briefly, $200 \mu \mathrm{g}$ myelin oligodendrocyte glycoprotein 35-55 $\left(\mathrm{MOG}_{35-55}\right.$ ) peptide (GL Biochem Corporation. Ltd., Shanghai) dissolved in $100 \mu \mathrm{l}$ phosphate-buffered saline (PBS) was emulsified with $100 \mu \mathrm{l}$ of complete Freund's adjuvant (Sigma, St Louis, MO) supplemented with $400 \mu \mathrm{g}$ of Mycobacterium tuberculosis H37Ra (Difco Laboratories, Detroit, MI). Then, 8-week-old mice were anesthetized by isoflurane and then immunized with the above emulsion via subcutaneous injection on day 0 . Pertussis toxin (Merck KGaA, Darmstadt) was administered intraperitoneally at 0 and 2 days post-immunization (dpi).

Clinical scores were monitored daily in a blind manner. Mice were scored on a scale of $0-5$ based on the degree of ascending paralysis [17]: 0, no symptoms; 0.5 , partial limp tail; 1 , complete limp tail; 1.5 , hind limb ataxia; 2, hind limb paresis; 2.5, partial hind limb paralysis; 3, complete hind limb paralysis; 3.5, hind limb paralysis and fore limb paresis; 4, hind and fore limb paralysis; 5 , moribund.

Analysis of plasma ADAMTS13 activity and VWF multimer Blood was obtained from mice at different times postEAE immunization and stored in tubes with $3.8 \%$ sodium citrate (at a ratio of 9:1 $\mathrm{vol} / \mathrm{vol}$ ). After centrifugation at $3000 \mathrm{~g}$ for $20 \mathrm{~min}$, plasma was stored at $-80{ }^{\circ} \mathrm{C}$ until analysis.

ADAMTS13 activity in plasma was determined using FRETS-VWF73 peptide (Peptides International) as previously described [18]. Briefly, FRETS-VWF73 was incubated with plasma in reaction buffer $(5 \mathrm{mM}$ Bis-Tris, $25 \mathrm{mM}$ $\mathrm{CaCl}_{2}, 0.005 \%$ Tween-20 [pH 6.0]). Fluorescence intensities were detected every $5 \mathrm{~min}$ for $1 \mathrm{~h}$ with a fluorescence spectrophotometer (Bio-Tech) using excitation at $340 \mathrm{~nm}$ and emission at $450 \mathrm{~nm}$. The analysis of ADAMTS13 activity in the cerebrospinal fluid (CSF) and spinal cords of mice with commercially available FRETS-VWF73 peptide was not satisfactory, and thus these analyses were precluded from our study.

The plasma VWF multimer was analyzed as previously described [18-20]. Mouse plasma $(4 \mu \mathrm{l})$ was diluted in $70 \mathrm{mM}$ Tris- $\mathrm{HCl}$ buffer $(16 \mu \mathrm{l}), \mathrm{pH} 6.5$ containing $2.4 \%$ sodium dodecyl sulfate, $4 \%$ urea, and $4 \mathrm{mM}$ EDTA and then heated at $60{ }^{\circ} \mathrm{C}$ for $20 \mathrm{~min}$. The sample $(20 \mu \mathrm{l})$ was fractionated on a $1.2 \%$ SeaKem HGT agarose mini-gel (Lonza) by electrophoresis and transferred onto a nitrocellulose membrane (Merck KGaA). The membrane was incubated with rabbit anti-human VWF antibody (DAkO) and then detected with horseradish peroxidaseconjugated anti-rabbit IgG. The signal was obtained using an ImageQuant LAS 4000 mini system (GE Healthcare).

\section{ADAMTS13 treatment}

Previous studies have confirmed the enzymatic activity of recombinant human ADAMTS13 in mice [21]; thus, recombinant human ADAMTS13 (R\&D systems) was adopted. Four days before ADAMTS13 treatment, mice were anesthetized by isoflurane, and a 26-gauge stainless steel guide cannula was implanted into the lateral ventricles $(0.2 \mathrm{~mm}$ posterior to bregma and $0.9 \mathrm{~mm}$ lateral to midline). In the preventive setting, a total of $50 \mathrm{EAE}$ mice were randomly divided into two groups: vehicle group and ADAMTS13 group. Vehicle $(2 \mu \mathrm{l}$ sterile phosphate-buffered saline, PBS) or ADAMTS13 (50 ng in $2 \mu \mathrm{l} \mathrm{PBS}$ ) was delivered into the lateral ventricles daily from $7 \mathrm{dpi}$ to $21 \mathrm{dpi}$. During the injection period between $7 \mathrm{dpi}$ and $21 \mathrm{dpi}$, the mortality rate was $8 \%$. To test the therapeutic effect, ADAMTS13 (50 ng in $2 \mu \mathrm{l}$ PBS) or vehicle $(2 \mu \mathrm{l}$ sterile PBS) was injected into the lateral ventricle of EAE mice for 15 days since the clinical score reached 1 ( $15 \mathrm{dpi})$.

\section{Tissue preparation}

On 22 and $30 \mathrm{dpi}$, mice were euthanized by pentobarbital. Then, mice were transcardially perfused with $0.1 \mathrm{M}$ PBS and fixed with 4\% paraformaldehyde (PFA). Lumbar spinal cords were resected, postfixed overnight in $4 \%$ PFA, and then cryoprotected in $20 \%$ and $30 \%$ sucrose solution at $4{ }^{\circ} \mathrm{C}$. Spinal cord sections were embedded in Tissue-Tek optimum cutting temperature (OCT) compound (Sakura Finetek, Torrance, CA, USA) and cut into 10-um-thick transverse sections with a freezing microtome (Leica CM1950). 


\section{Histopathology}

Spinal cord sections were stained with luxol fast blue (LFB) for the detection of demyelination and hematoxylin and eosin (H\&E) for the assessment of inflammation. Briefly, sections were incubated with $0.1 \%$ LFB (Sigma, St Louis, MO) at $60{ }^{\circ} \mathrm{C}$ overnight and differentiated in $0.1 \%$ lithium carbonate solution and $70 \%$ ethyl alcohol. Quantification of demyelination was performed by tracing the areas resistant to the LFB stain and dividing the area by the total white matter area using Image-Pro Plus software. H\&E stained sections were scored in a semiquantitative fashion for inflammation: 0 , none; 1 , a few inflammatory cells; 2 , organization of perivascular infiltrates; and 3 , perivascular cuffing with extension into the adjacent tissue [22]. For quantification of LFB and HE, four to five serial sections from every mouse were examined.

\section{Immunofluorescence}

For immunofluorescence, spinal cord sections from EAE mice were incubated in blocking solution (3\% donkey serum in PBS) containing $0.3 \%$ Triton X-100 at room temperature for $30 \mathrm{~min}$. Then, sections were stained overnight at $4{ }^{\circ} \mathrm{C}$ with primary anti-CD3e (R\&D systems), anti-Iba-1 (Abcam), anti-Ly6G (BD Biosciences), and anti-VWF (DAKO) antibodies. Alexa Fluor 488coupled donkey antibodies (Abcam) or Alexa Fluor 555coupled donkey antibodies (Abcam) were used as secondary antibodies, and DNA in the nucleus was stained with DAPI (CST). Sections were imaged by fluorescence microscopy (IX53, Olympus). The analyses of immune cell markers (CD3 and Ly6G) were quantified by the number of positive cells per field, a $200 \mu \mathrm{m} \times 150 \mu \mathrm{m}$ rectangle. For analysis of Iba-1 mean fluorescence intensity with Image-Pro Plus software, all sections were immunolabeled and collected as a single batch using the same parameters. For every EAE mouse, the values were averaged from 15 fields covering the white matter of three spinal cord sections.

\section{Flow cytometry}

In a preventive setting at $22 \mathrm{dpi}$, blood was collected in EDTA-coated tubes via cardiac puncture in mice overdosed with sodium pentobarbital. Spleens were ground and passed through a 70- $\mu \mathrm{m}$ nylon mesh cell strainer (BD Biosciences) to obtain a single cell suspension for further processing. Spinal cords were harvested from PBS-perfused mice and then ground and filtered through a $70-\mu \mathrm{m}$ strainer. Leukocyte cells were isolated by $30 \%$ and $70 \%$ Percoll gradient (GE Healthcare).

FITC-conjugated anti-CD3e, PerCP-Cy5.5-conjugated anti-CD4, PerCP-Cy5.5-conjugated anti-CD11b, APCconjugated anti-CD45, PE-conjugated anti-Ly6G, PECy7-conjugated anti-Ly6C, PE-conjugated anti-IL-17A, and APC-conjugated IFN- $\gamma$ antibodies were purchased from eBioscience. To analyze inflammatory cells in EAE mice, cells isolated from the blood, spleen, and spinal cord were blocked with anti-CD16/CD32 mix (BD Biosciences) and then stained with anti-CD45, anti-CD11b, anti-CD3e, anti-Ly6G, and anti-Ly6C antibodies on ice for $30 \mathrm{~min}$. Zombie Violet ${ }^{\mathrm{mt}}$ (Biolegend) was used to distinguish live from dead cells. For analysis, doublets and dead cells were discarded, and leukocytes were identified as follows: $\mathrm{T}$ lymphocytes $\left(\mathrm{CD} 45^{\mathrm{hi}} \mathrm{CD}_{11 b^{-}} \mathrm{CD}^{+}\right)$, microglia $\left(\mathrm{CD} 45^{\text {mild }} \mathrm{CD} 11 \mathrm{~b}^{+}\right)$, neutrophils $\left(\mathrm{CD} 45^{\text {hi }}\right.$ $\mathrm{CD}_{11 b^{+}}$Ly6C $^{\text {int }}$ Ly6G $\left.{ }^{\text {hi }}\right)$, and monocytes $\left(\mathrm{CD} 45^{\text {hi }}\right.$ $\mathrm{CD}_{11 b^{+}}$Ly6C $^{\text {hi }}$ Ly6G $^{-}$). Among these CD $45^{\text {hi }}$ leukocytes infiltrated into spinal cords, $\mathrm{T}$ lymphocytes, neutrophils, and monocytes were pre-gated on CD $45^{\text {hi }}$ cells.

For intracellular staining, cells from spleens were harvested and stimulated in complete media (RPMI media containing $10 \%$ FCS) for $5 \mathrm{~h}$ at $37{ }^{\circ} \mathrm{C}$ with Cell Stimulation Cocktail (plus protein transport inhibitors) (eBioscience). Subsequently, cells were stained with antiCD3e and anti-CD4 antibodies, fixed and permeabilized using Fixation and Permeabilization Buffer Set (eBioscience), and then stained with anti-IL-17A and anti-IFN- $\gamma$ antibodies. Stained cells were acquired using a CytoFLEX flow cytometer (Beckman), and data were analyzed with CytExpert software (Beckman).

\section{Analysis of blood-spinal cord barriers}

At $22 \mathrm{dpi}$, mice were randomly selected for assessment of blood-spinal cord barrier (BSCB) permeability using the Evans blue extravasation method. Briefly, 2\% Evans blue (EB; Sigma, St Louis, MO) dissolved in saline was intravenously injected into the EAE mice at a dose of $2 \mathrm{ml} / \mathrm{kg}$ via the tail vein. Three hours later, the mice were anesthetized with pentobarbital and then perfused with PBS. Spinal cord tissues were collected, and wet weights were measured. Tissues were homogenized in $N$, $\mathrm{N}$-dimethylformamide (Sigma). After $24 \mathrm{~h}$ of incubation to extract dye at $37^{\circ} \mathrm{C}$, the samples were centrifuged at $21,000 \times g$ for $30 \mathrm{~min}$. The absorbance of Evans blue in the supernatant was then measured with an $\mathrm{Epoch}^{\mathrm{mi}} \mathrm{Mi}$ croplate Spectrophotometer (Bio-Tek) at $620 \mathrm{~nm}$ and $740 \mathrm{~nm}$. Background absorbance, calculated as -log OD620 $=(0.964)(-\log$ OD740) -0.0357 , was subtracted as previously described [23]. Dye concentrations were calculated from a standard curve. The data were expressed as $\mu \mathrm{g} / \mathrm{g}$ of tissue weight.

\section{Quantitative real-time PCR}

Total RNA was isolated from lumbar spinal cords using TRIzol reagent (Thermo Fisher Scientific) according to the manufacturer's instructions. cDNA was synthesized from 300 ng total RNA using ReverTra Ace qPCR RT Master Mix with gDNA Remover (Toyobo, Osaka, 
Japan). Real-time quantitative PCR was performed using the Applied Biosystems 7500 Real-Time PCR System with SYBR ${ }^{\circ}$ Green Real-time PCR Master Mix (Toyobo, Osaka, Japan). Actin was measured as a housekeeping gene. The relative gene expression ratio was calculated based on the $2^{\text {-deltadeltaCT }}$ method. Measurements were performed in duplicate. The nucleotide sequences of the primers are listed in Table 1.

\section{Measurement of interleukin-1 $\beta$, IL-17, and IFN- $\gamma$ protein levels in the spinal cord by enzyme-linked immunosorbent assay}

The spinal cords were isolated and homogenized on ice in PBS buffer containing protease inhibitor cocktail (Thermo Fisher Scientific). Lysates were centrifuged at $4{ }^{\circ} \mathrm{C}$ for $10 \mathrm{~min}$ at $12,000 \times g$. Supernatants were collected, and protein concentrations were determined using a BCA protein assay kit (Thermo Fisher Scientific). Protein levels of interleukin-1 $\beta$ (IL-1 $\beta$ ), IL-17, and IFN- $\gamma$ were measured using enzyme-linked immunosorbent assay (ELISA) kits (RayBiotech) according to the manufacturer's protocols. Samples were read with an Epoch ${ }^{\text {тм }}$ Microplate Spectrophotometer (Bio-Tek) at $450 \mathrm{~nm}$. The concentration was determined by comparison to a standard curve.

\section{Statistical analysis}

Values are expressed as the means \pm standard error of the mean (SEM). Parametric data were analyzed using Student's $t$ test for two groups and one-way ANOVA followed by Dunnett's posttest for multiple groups. Nonparametric data were analyzed using the Mann-Whitney $U$ test. All statistical analyses were performed using GraphPad Prism 5.0 (GraphPad Software), and $P<0.05$ was considered significant.

\section{Results}

Plasma ADAMTS13 activities and VWF levels in EAE mice

To evaluate the role of ADAMTS13 in the development of EAE, the kinetics of plasma ADAMTS13 activity were quantified at different time points. Compared to the naïve group, relative ADAMTS13 activity in EAE mice was obviously reduced at $7 \mathrm{dpi}(75.4 \pm 6.3 \%$; $P<0.01)$, remaining low at $14 \mathrm{dpi}(73.2 \pm 3.3 \% ; \quad P<0.01)$.

Table 1 Primers sequences used for RT-PCR

\begin{tabular}{|c|c|c|}
\hline Gene & Primer sequence $\left(5^{\prime}\right.$ to $\left.3^{\prime}\right)$ & \\
\hline & Forward & Reverse \\
\hline$\beta$-actin & GAGACCTTCAACACCCCAGC & ATGTCACGCACGATTTCCC \\
\hline Cxcl1 & CACAGGGGCGCCTATCGCCAA & CAAGGCAAGCCTCGCGACCAT \\
\hline $\mathrm{Ccl} 2$ & CCTGCTGTTCACAGTTGCC & ATTGGGATCATCTTGCTGGT \\
\hline $\mid L-1 \beta$ & GCTTCAGGCAGGCAGTATCA & TGCAGTTGTCTAATGGGAACG \\
\hline WWF & CAGACAGACGCCATCTCCAG & TGCAAGCTGTAGGCAAGCAT \\
\hline
\end{tabular}

Unpredictably, ADAMTS13 activity at 21 dpi was slightly increased but still lower than that in the naive group (79.0 $\pm 5.5 \% ; P<0.05)$ (Fig. $1 \mathrm{a}$ ).

Thus far, the only known activity of ADAMTS13 is to cleave large VWF multimers into smaller ones; thus, plasma VWF multimers were assessed in EAE mice. Compared to naïve mice, EAE mice at 14 dpi had a significant increase in the level of ultra large VWF (ULVWF) (Fig. 1b). Moreover, there was a substantial increase in the level of low-molecular-weight VWF (LMW-VWF) in the plasma of EAE mice at $14 \mathrm{dpi}$ compared to that in naïve mice (Fig. 1b).

\section{Preventive treatment with ADAMTS13 ameliorates EAE clinical score}

To test our hypothesis that ADAMTS13 may exert protective effects on EAE mice, we injected EAE mice with ADAMTS13 or vehicle from $7 \mathrm{dpi}$ to $21 \mathrm{dpi}$. The mean clinical score of ADAMTS13-treated mice at 21 dpi was significantly lower than that of vehicle-treated mice (Fig. 2a, Additional file 1). Furthermore, the cumulative clinical score summed from $7 \mathrm{dpi}$ to $21 \mathrm{dpi}$ was significantly reduced by ADAMTS13 treatment (Fig. 2b). There was a reduction in the maximum clinical score (vehicle: $3.4 \pm 0.1$ vs. ADAMTS13: $2.4 \pm 0.2 ; P=0.0002$, Fig. 2c). However, there was no difference in the disease onset day between ADAMTS13-treated mice and the vehicle group. Subsequently, we investigated the preventive effect of ADAMTS13 on demyelination in the spinal cord through LFB staining. The extent of demyelination was much lower in the ADAMTS13-treated mice compared with that in the mice treated with vehicle (Fig. $2 \mathrm{~d}, \mathrm{e}$ ).

\section{Preventive ADAMTS13 treatment reduces the inflammatory burden in the spinal cord of EAE mice}

To determine how ADAMTS13 treatment ameliorated the EAE clinical score, we isolated leukocytes from the spinal cords of EAE mice at $22 \mathrm{dpi}$ and quantified $\mathrm{CD} 45^{+}$leukocytes. Both innate and adaptive immune reactions have been believed to take part in MS and EAE pathogenesis [24]. Thus, we analyzed the infiltration of different leukocyte subsets into spinal cords via flow cytometry and the gating strategy is shown in Fig. 3a. The total number of immune cells in the spinal cords of EAE mice was obviously reduced by ADAMTS13 treatment (Fig. 3b). Moreover, the absolute numbers of T lymphocytes, neutrophils, and monocytes decreased clearly in ADAMTS13 group compared to those in vehicle group (Fig. 3b). But the difference of microglia numbers between two groups did not reach statistical significance. Among these CD $45^{\text {hi }}$ leukocytes infiltrated into spinal cords, the proportions of $\mathrm{T}$ lymphocytes, neutrophils, and monocytes were not significantly reduced by preventive ADAMTS13 administration (Fig. 3b). 

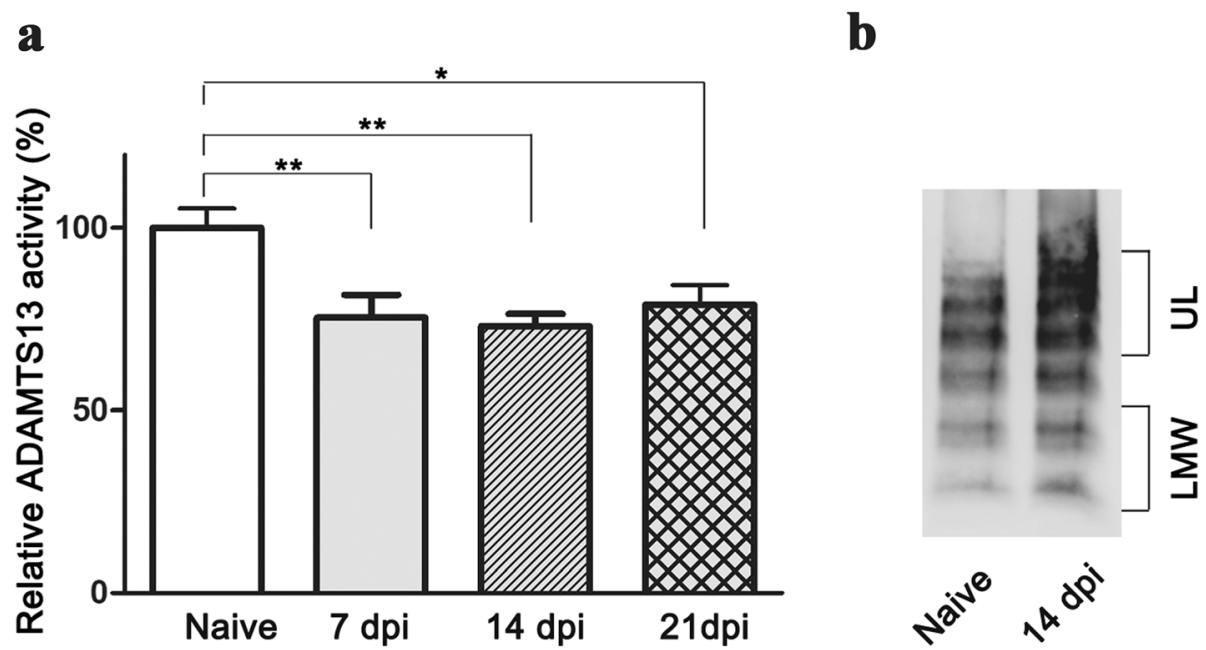

Fig. 1 Reduced ADAMTS13 activity and increased WWF levels in the plasma of EAE mice. Plasma was obtained from naïve and EAE mice at different times. a Relative ADAMTS13 activities from EAE and naïve mice are shown. $\mathbf{b}$ WWF levels from the plasma of naïve and EAE mice are shown by western blot. The results are expressed as the mean $\pm \operatorname{SEM}(n=6)$. Statistical significance was determined by one-way ANOVA followed by Dunnett's posttest. ${ }^{*} P<0.05$; ${ }^{*} P<0.01$. dpi day post immunization, LMW low molecular weight WWF, UL ultra large VWF

We next assessed the localization of infiltrated leukocytes via immunofluorescence staining of frozen spinal cord sections from EAE mice at $22 \mathrm{dpi}$. Interestingly, cells expressing CD3 (T lymphocyte marker) or Ly6G (neutrophil marker) were consistently detected around blood vessels in the white matter (Fig. 3c). In line with the flow cytometry results, ADAMTS13 administration dramatically reduced the numbers of CNS-infiltrating $\mathrm{T}$ lymphocytes and neutrophils, without affecting the microglia marker Iba-1 immunofluorescence intensity (Fig. 3d).

To further characterize the effect of ADAMTS13 on immune modulation, we conducted an analysis of cytokine and chemokine levels by ELISA and real-time quantitative PCR of the lumbar spinal cord of EAE mice harvested at $22 \mathrm{dpi}$ in the preventive setting. First, compared to vehicle-treated mice, significantly lower levels of CXCL1 and CCL2 expression were detected in ADAMTS13treated EAE mice, consistent with reduced neutrophil, monocyte, and $\mathrm{T}$ lymphocyte infiltration into the spinal cords (Fig. 4a). Second, in mice that received ADAMTS13, IL-1 $\beta$ expression was dramatically reduced at both the RNA and protein levels (Fig. 4a, b). Furthermore, the level of IL-17 protein was dramatically reduced by ADAMTS13 treatment (Fig. 4b). In contrast, IFN- $\gamma$ levels appeared to be unaffected by ADAMTS13 treatment (Fig. 4b). Collectively, these results suggest a strong anti-inflammatory effect of preventive ADAMTS13 treatment in EAE mice.

\section{ADAMTS13 decreases VWF levels in spinal cords of EAE mice}

To date, the only known enzymatic activity of ADAMTS13 is to cleave large VWF multimers into smaller ones. To study the potential mechanisms of ADAMTS13 treatment on cell infiltration into the spinal cords of EAE mice, VWF levels in the spinal cords of EAE mice were assessed. First, immunofluorescence staining showed that VWFpositive areas in the spinal cords of EAE mice were surrounded by numerous infiltrating leukocytes detected via DAPI staining (Fig. 5a). Compared with vehicle, ADAMTS13 preconditioning reduced the VWF levels, along with a reduced number of infiltrating leukocytes (Fig. 5a). Second, increased VWF expression levels were detected by real-time PCR in the spinal cords of EAE mice at 21 dpi compared to levels in the naïve mice (Fig. 5b). VWF expression levels were significantly decreased in EAE mice treated with ADAMTS13 compared with vehicle (Fig. 5b). Together, these results confirmed our hypothesis that ADAMTS13 reduces cellular recruitment into the spinal cords of EAE mice through its proteolytic effect on VWF.

\section{Preventive ADAMTS13 treatment preserves blood-spinal cord barriers of EAE mice}

Recent studies have confirmed the effect of the ADAMTS13-VWF axis on blood-brain barrier (BBB) permeability in mice with stroke and traumatic brain injury $[13,16,25]$. However, whether ADAMTS13 administration preserved the compromised blood-spinal cord barrier (BSCB) in EAE mice is unknown. To assess the degree of BSCB disruption, EAE mice were injected intravenously with Evans blue at $22 \mathrm{dpi}$, and then, spinal cords were measured for the amount of Evans blue. Statistical tests revealed that Evans blue content in vehicletreated EAE mice $(7.26 \pm 0.65 \mu \mathrm{g} / \mathrm{g}$ of tissue) was dramatically higher compared to that in the naïve group 


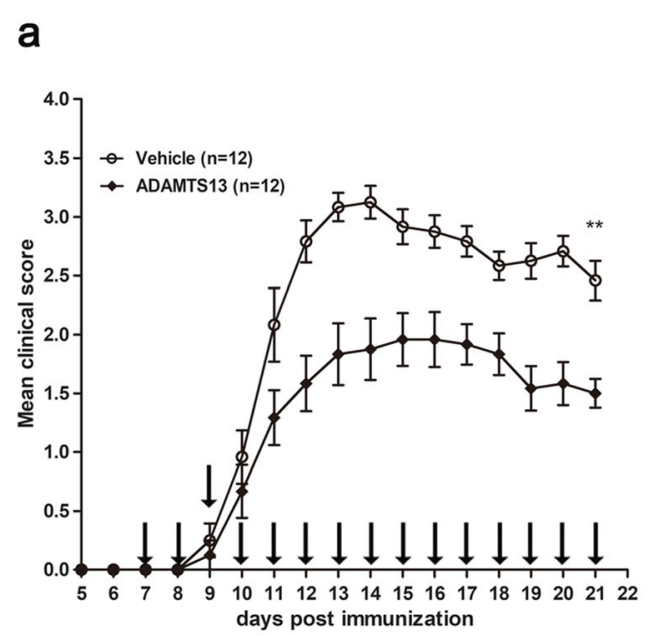

b

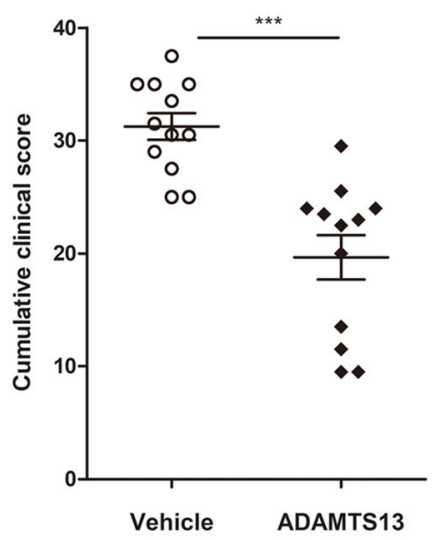

C

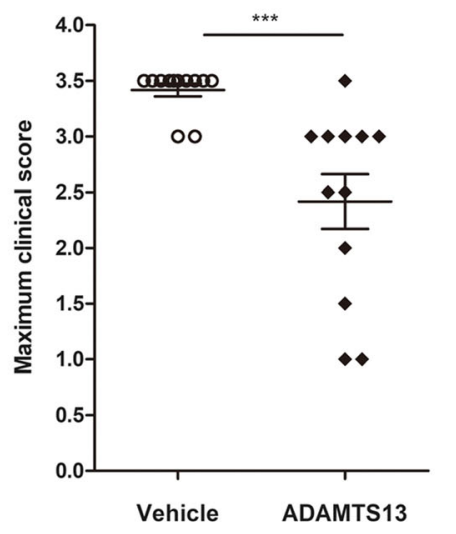

d
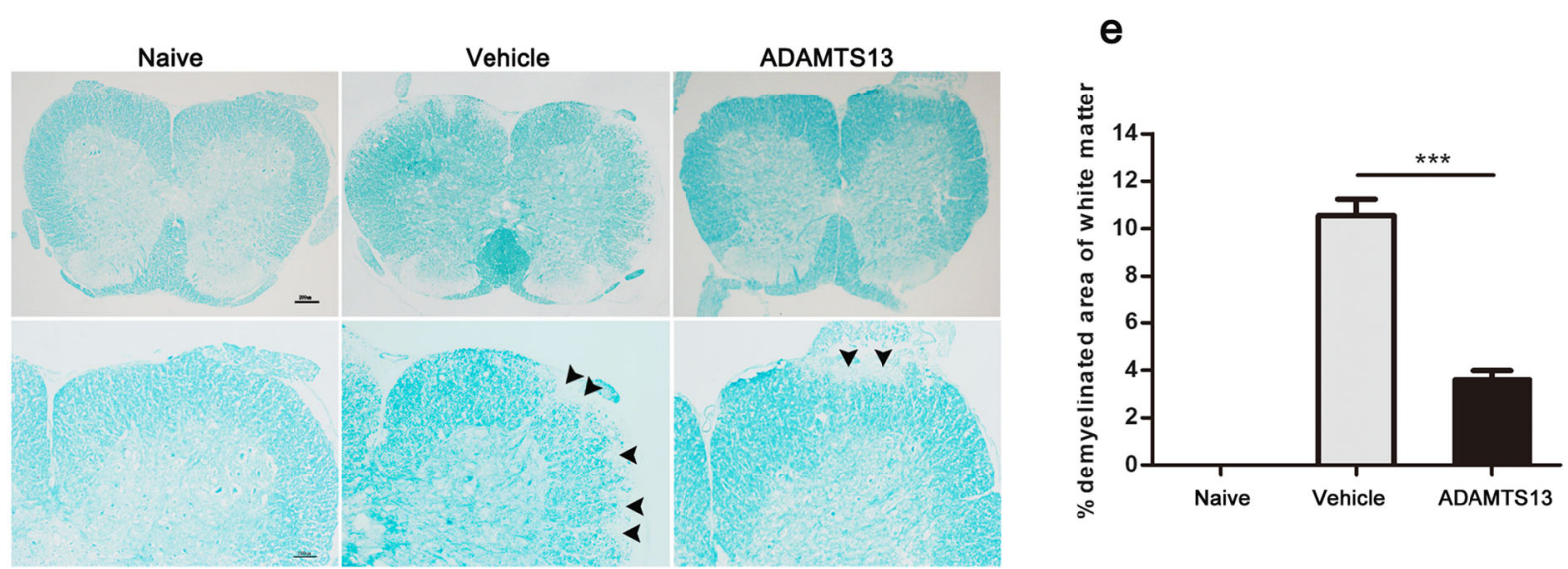

Fig. 2 Preventive treatment with ADAMTS13 reduces clinical scores and preserves myelin in EAE mice. ADAMTS13 (50 ng in $2 \mu l$ PBS) or vehicle (2 $\mu$ l PBS) was injected as a preventive treatment into the lateral ventricle of EAE mice every day from $7 \mathrm{dpi}$ to $21 \mathrm{dpi}$. $\mathbf{a}$ The daily mean clinical score is shown, and the mean clinical scores at $21 \mathrm{dpi}$ were compared between vehicle and ADAMTS13 group $(* * P<0.01)$. b Cumulative clinical scores were summed by adding daily clinical scores from $7 \mathrm{dpi}$ to $21 \mathrm{dpi}$. c The maximum clinical score of every EAE mouse was compared between groups. Data are from a single experiment representative of two independent experiments (a-c). ADAMTS13- or vehicle-treated EAE mice were sacrificed at 22 dpi, and lumbar spinal cord tissues were harvested. $\mathbf{d}$ Sections of lumbar spinal cords from EAE mice were subjected to LFB staining for assessment of demyelination and arrowheads show demyelinating lesions. Bars represent $100 \mu \mathrm{m}$ (the upper panels) and $200 \mu \mathrm{m}$ (the lower panels). e The extent of demyelination was compared between ADAMTS13- and vehicle-treated EAE mice ( $n=4$ each group). Values are expressed as mean \pm SEM. Statistical significance was determined by the Mann-Whitney $U$ test for clinical scores and by Student's $t$ test for percent demyelination. ${ }^{* *} P<0.01$; ${ }^{* * *} P<0.001$

$(0.34 \pm 0.07 \mu \mathrm{g} / \mathrm{g})$. Furthermore, Evans blue leakage in EAE mice was significantly reduced by ADAMTS13 treatment (3.82 $\pm 0.20 \mu \mathrm{g} / \mathrm{g}$ of tissue) (Fig. $5 \mathrm{c}$ ).

\section{Preventive ADAMTS13 treatment does not affect the peripheral inflammatory response of EAE}

Another possible explanation for the reduced CNS inflammatory burden with ADAMTS13 could be the reduced number of peripheral immune cells in the blood and spleen. To test this, we assessed peripheral blood (Fig. 6a) and spleen (Fig. 6b) for T lymphocytes (CD45 ${ }^{\text {hi }}$ $\left.\mathrm{CD} 11 \mathrm{~b}^{-} \mathrm{CD}^{+}\right)$, neutrophils $\left(\mathrm{CD} 45^{\mathrm{hi}} \mathrm{CD} 1 \mathrm{~b}^{+} \mathrm{Ly} 6 \mathrm{C}^{\mathrm{int}}\right.$ Ly6G $^{\text {hi }}$ ), and monocytes (CD45 ${ }^{\text {hi }} \mathrm{CD}_{11 b^{+}}$Ly6C $^{\text {hi }}$ Ly6G $^{-}$) by flow cytometric analysis. However, ADAMTS13treated EAE mice had comparable percentages of inflammatory cells to those treated with vehicle (Fig. 6c). Furthermore, we examined the effect of ADAMTS13 on $\mathrm{CD} 4 \mathrm{~T}$ cell differentiation via intracellular cytokine staining and flow cytometric analysis of splenocytes at 22 dpi. The data showed a mild decrease in the frequency of IFN- $\gamma$-producing Th1 cells in ADAMTS13treated mice, but the decrease did not reach statistical significance (Fig. 6d). The frequency of IL-17-producing Th17 cells were not different between ADAMTS13treated and vehicle-treated mice (Fig. 6d). Above all, neither a significant difference in the cell ratio nor a 
a
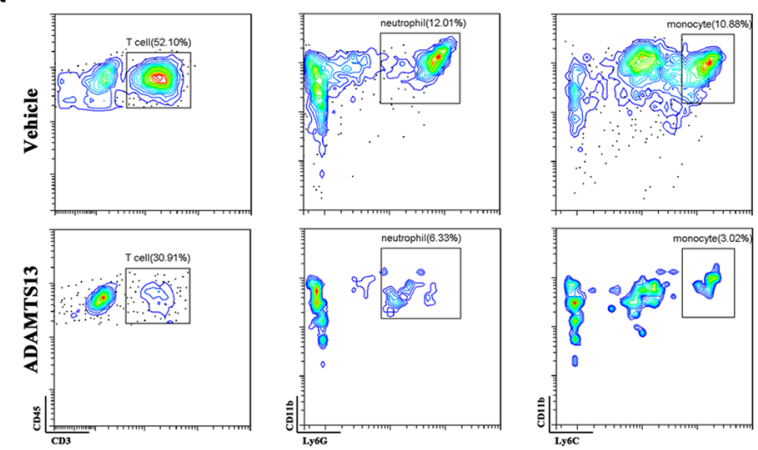

b
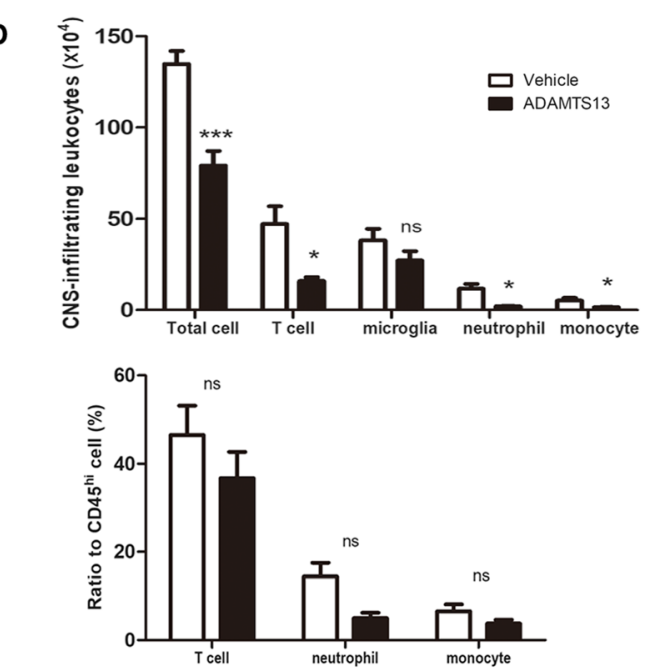

C
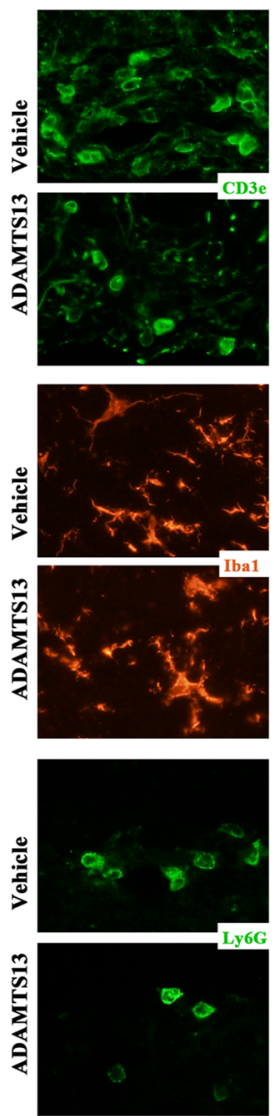
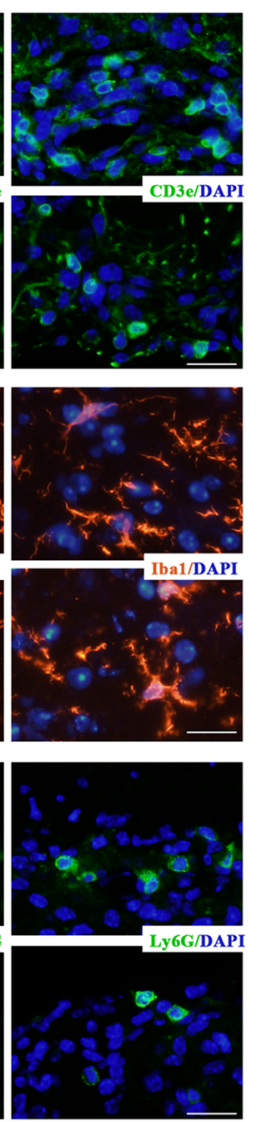

d
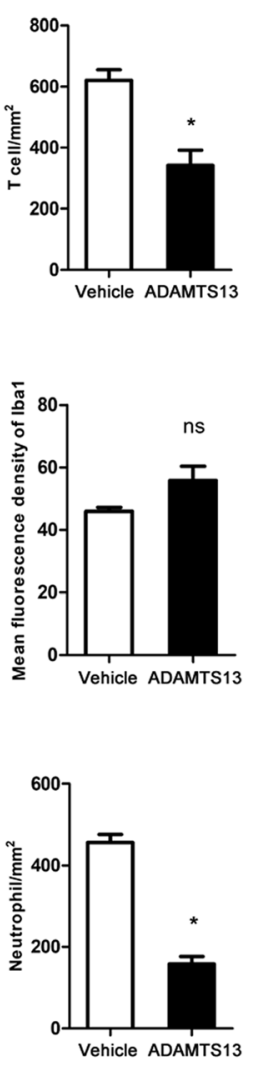

Fig. 3 Effect of preventive ADAMTS13 treatment on leukocyte infiltration into the spinal cords of EAE mice. The whole spinal cords from ADAMTS13or vehicle-treated EAE mice at $22 \mathrm{dpi}$ were isolated and measured by flow cytometry $(\mathbf{a}, \mathbf{b})$. Leukocyte populations were gated as follows: $T$

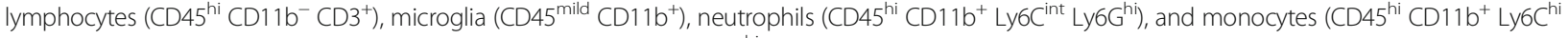
Ly $6 \mathrm{G}^{-}$). a Representative plots of leukocyte subsets (pre-gated on $\mathrm{CD} 45^{\text {hi }}$ leukocytes) in the spinal cords from EAE mice treated with vehicle or ADAMTS13. $\mathbf{b}$ The numbers and frequencies of leukocyte subsets compared to CD45 leukocytes in the spinal cords of EAE mice ( $n=6$ each group). $\mathbf{c}$ Representative immunofluorescence images of spinal sections from EAE mice at $22 \mathrm{dpi}$ are shown. Tissue sections were stained with antibodies against CD3 (upper; green, T lymphocytes), Iba1 (middle; red, macrophages/microglia), and Ly6G (bottom; green, neutrophils). DAPI was used to stain the nucleus (blue staining). Bars, $20 \mu \mathrm{m}$. d Quantitative analysis of immunofluorescence images is shown ( $n=4$ each group). Values are expressed as the mean $\pm S E M$, and Student's $t$ test was used to compare differences between groups. ${ }^{*} P<0.05$; ${ }^{* * *} P<0.001 ; n s$ no significance

difference in CD4 T cell differentiation toward Th1 and Th17 was detected between ADAMTS13-treated and vehicle-treated EAE mice.

\section{Protective effects of ADAMTS13 treatment on established EAE mice}

The finding that plasma ADAMTS13 activity sustained low at $14 \mathrm{dpi}$ suggests the therapeutic potential of ADAMTS13 for EAE. To test this hypothesis, ADAMTS13 or vehicle was injected once the clinical score reached 1 (from 15 dpi to 29 dpi). ADAMTS13 administration markedly reduced the mean clinical score of EAE mice at 29 dpi compared with the vehicle (Fig. 7a). Furthermore, ADAMTS13 treatment also led to a decrease in the cumulative clinical score (from 15 dpi to $29 \mathrm{dpi}$ ) (Fig. 7b) and maximum clinical score (vehicle: $2.5 \pm 0.2$ vs. ADAMTS13: $1.8 \pm 0.1 ; P=0.0011$, Fig. 7c). Subsequently, we performed LFB and HE analyses of spinal cord sections from vehicle and ADAMTS13-treated EAE mice at $30 \mathrm{dpi}$, and representative images of LFB and HE staining are shown in Fig. 7d. Compared to naïve mice (Fig. 7d, left), substantial demyelination of white matter and extensive inflammatory cell infiltration of spinal cord tissue were observed in EAE mice treated with vehicle (Fig. 7d, middle). In contrast, significant reductions in the extent of demyelination and inflammatory cell infiltration were detected in the spinal cords of ADAMTS13-treated versus vehicle-treated mice (Fig. 7d). Moreover, immunofluorescence staining of the spinal cord sections at 30 dpi showed that the VWF level, along with the number of infiltrating leukocytes, was reduced by ADAMTS13 

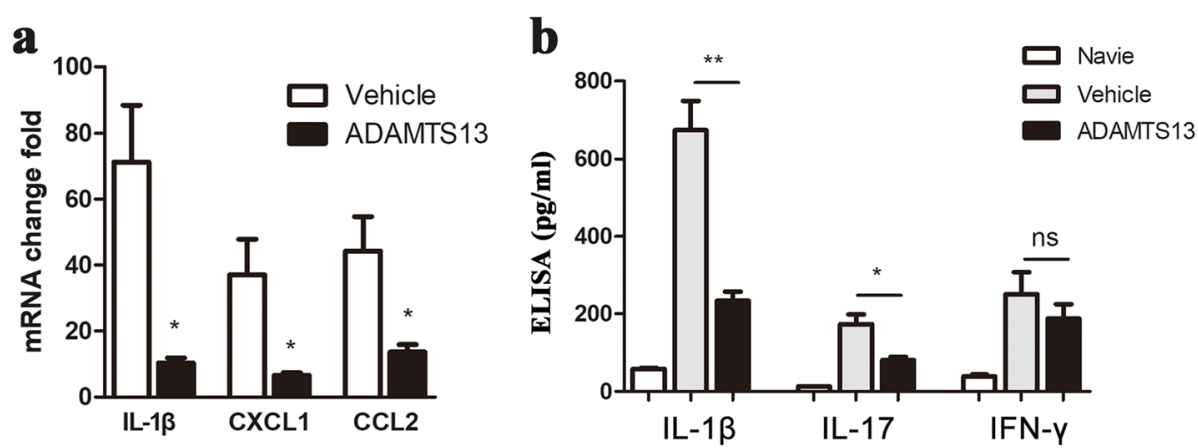

Fig. 4 Effect of preventive ADAMTS13 treatment on inflammatory factors in EAE mice. a Quantitative RT-PCR analysis of IL-1 $13, C X C L 1$, and CCL2 mRNA levels in the spinal cords of ADAMTS13- and vehicle-treated EAE mice at $22 \mathrm{dpi}$. Data represent fold changes compared to the spinal cords of naïve mice. $\mathbf{b}$ Supernatants obtained from spinal cord homogenates from naïve, ADAMTS13- and vehicle-treated EAE mice at $22 \mathrm{dpi}$ were subjected to ELISA kits for IL-1 $\beta, I L-17$, and IFN- $\gamma$. The results are expressed as inflammatory factor concentrations, averaged by the total protein contents of the supernatants. Values are expressed as the mean \pm SEM $(n=5-6)$ and Student's $t$ test was used to compare differences between groups. ${ }^{*} P<0.05 ;{ }^{*} P<0.01 ;$ ns, no significance

treatment (Fig. 7e). To evaluate the therapeutic effect of ADAMTS13 on immune modulation, we further analyzed cytokine and chemokine levels by real-time quantitative PCR of the lumbar spinal cord of EAE mice harvested at $30 \mathrm{dpi}$. Compared to vehicle-treated mice, ADAMTS13-treated EAE mice had distinctly lower expression levels of IL-1 $\beta$, CXCL1, and CCL2 (Fig. 7f), consistent with reduced inflammatory cell infiltration into the spinal cords.

\section{Discussion}

Decreased ADAMTS13 levels were previously identified in the plasma from patients with many conditions, such as systemic inflammation [26, 27], stroke [28], and MS [9]. However, the importance of decreased ADAMTS13 levels in the plasma of MS patients has not been fully assessed, which prompted us to test the role of ADAMTS13 in autoimmune diseases, such as EAE. Here, for the first time, decreased ADAMTS13 activity was detected in the plasma of EAE mice immunized with $\mathrm{MOG}_{35-55}$ peptide. Moreover, we demonstrated that exogenous ADAMTS13 treatment attenuated the development and severity of EAE mice. Histopathological analysis showed alleviated demyelination and inflammatory changes in the spinal cords of ADAMTS13 treated EAE mice.

Consistent with decreased ADAMTS13 levels in the plasma from MS patients [9], we demonstrated that $\mathrm{MOG}_{35-55}$ immunized EAE mice had decreased ADAMTS13 activity in plasma. However, the mechanism of decreased ADAMTS13 levels and activity in the plasma of MS patients and EAE mice has not been fully assessed. First, Reiter and colleagues reported the inverse correlation between decreased ADAMTS13 activity and increased VWF-related parameters, suggesting a consumption of ADAMTS13 after the desmopressin or endotoxin induced release of higher multimers of VWF [27, 29]. Consistent with this notion, decreased ADAMTS13 activity and upregulated VWF levels in the plasma of EAE mice were observed in our study. Second, several inflammatory cytokines such as IFN- $\gamma$, tumor necrosis factor- $\alpha$ (TNF- $\alpha$ ), and IL-4, which are markedly elevated in MS patients and EAE mice [22], are known to suppress ADAMTS13 biosynthesis and secretion from hepatic stellate cells and endothelial cells [30]. Additionally, IL-6 was reported to inhibit the VWFcleaving activity of ADAMTS13 [31]. Finally, a number of recent studies demonstrated that interferon treatment reduced ADAMTS13 levels in MS patients [32, 33]. In contrast, other studies did not discover a connection between interferon treatment in MS and decreased ADAMTS13 levels $[9,34]$. In conclusion, it is speculated that the reduced ADAMTS13 activity may result from the consumption of substantial VWF released from activated endothelial cells in MS patients and EAE mice. However, we could not exclude the direct effect of inflammatory cytokines on ADAMTS13 activity. Further studies are required to determine the relationship between interferon treatment and ADAMTS13 levels.

Moreover, we demonstrated that exogenous ADAMTS13 treatment suppressed the development and severity of EAE mice by alleviating demyelination and the inflammatory response in the spinal cord. Our results showed that ADAMTS13 treatment obviously reduced the total number of immune cells in the spinal cords of EAE mice. Although the ratios to $\mathrm{CD} 45^{\text {hi }}$ infiltrating cells were not clearly reduced, the absolute numbers of T lymphocytes, neutrophils, and monocytes were clearly decreased in ADAMTS13 group. In line with the reduced number of immune cells, our study detected significantly lower levels of CXCL1, CCL2, and IL-1 $\beta$ in the spinal cords of ADAMTS13treated EAE mice. It has been commonly confirmed that not only $\mathrm{CD}_{4}^{+} \mathrm{T}$ cell but also neutrophils and monocytes play a role in MS and EAE $[3,35,36]$. As $\mathrm{CD} 4^{+} \mathrm{T}$ cell 

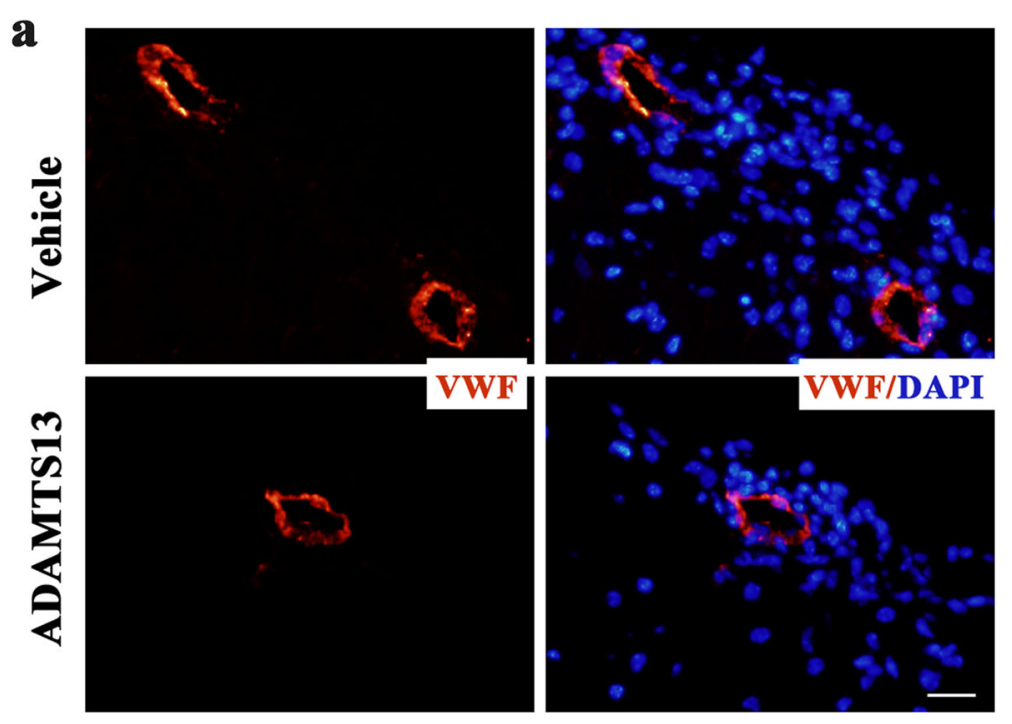

b

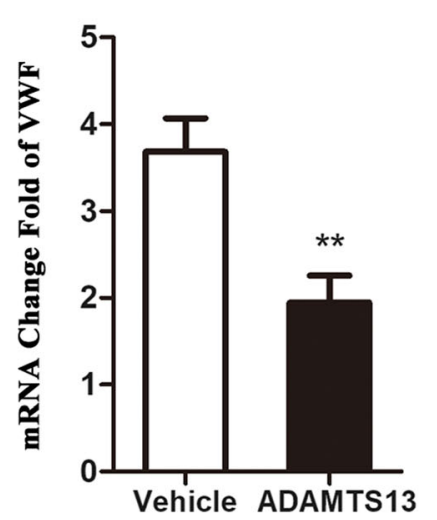

C

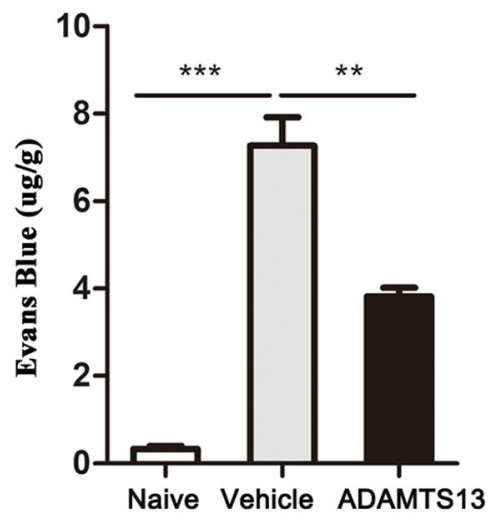

Fig. 5 Preventive ADAMTS13 treatment reduced WWF levels in spinal cords and preserved blood-spinal cord barriers (BSCBs) of EAE mice. a Tissue sections of spinal sections from EAE mice at 22 dpi were stained with antibodies against WWF (red) and DAPI (blue, nucleus). Bars, $20 \mu \mathrm{m}$. $\mathbf{b}$ Quantitative RT-PCR analysis of WWF mRNA levels in spinal cords of EAE mice at $22 \mathrm{dpi}$. Data represent fold change compared to the spinal cords of naïve mice. c Mice received intravenous an Evans blue injection at $22 \mathrm{dpi}$, and the amount of Evans blue was averaged by the weights of spinal cord tissue. Values are expressed as the mean \pm SEM ( $n=5-6$ each group). Student's $t$ test (b) and one-way ANOVA followed by Dunnett's posttest (c) were used to compare differences. ${ }^{* *} P<0.01$; ${ }^{* * *} P<0.001$

subsets, T helper 17 (Th17) cells and Th1 cells produce IL17 and IFN- $\gamma$, respectively, to mediate inflammation and autoimmunity $[3,37]$. In our study, ADAMTS13 treatment evidently reduced the protein levels of IL-17 in the spinal cords of EAE mice, but the decreased levels of IFN- $\gamma$ were not statistically significant. No change in IFN- $\gamma$ expression despite significantly reduced $\mathrm{T}$ cell in spinal cords might be explained with other IFN- $\gamma$ producing cells such as natural killer (NK) cells [38]. It has been increasingly recognized that NK cells play a role in EAE [39-41]. Further studies are required to determine whether NK cells in EAE mice are affected by ADAMTS13 treatment.

However, it is not fully understood how ADAMTS13 mitigates inflammatory cells infiltration into the spinal cords of EAE mice. Based on the results of a previous study showing that ADAMTS13 deficiency promotes leukocyte rolling in inflamed venules and extravasation in tissues via increased VWF activity [42], we hypothesize that ADAMTS13 reduces cellular recruitment into the spinal cords of EAE mice through VWF. In our study, increased VWF expression levels were detected in the spinal cords of EAE mice. Moreover, both preventive and therapeutic ADAMTS13 treatment reduced VWF levels, together with decreased leukocytes around VWF-positive areas. In line with our results, numerous studies have reported that ADAMTS13 obviously reduced inflammation in atherosclerosis [20, 43, $44]$ and stroke [12, 15] via cleaving active VWF. In addition, VWF has been closely associated with platelet adhesion and aggregation, which has recently been 


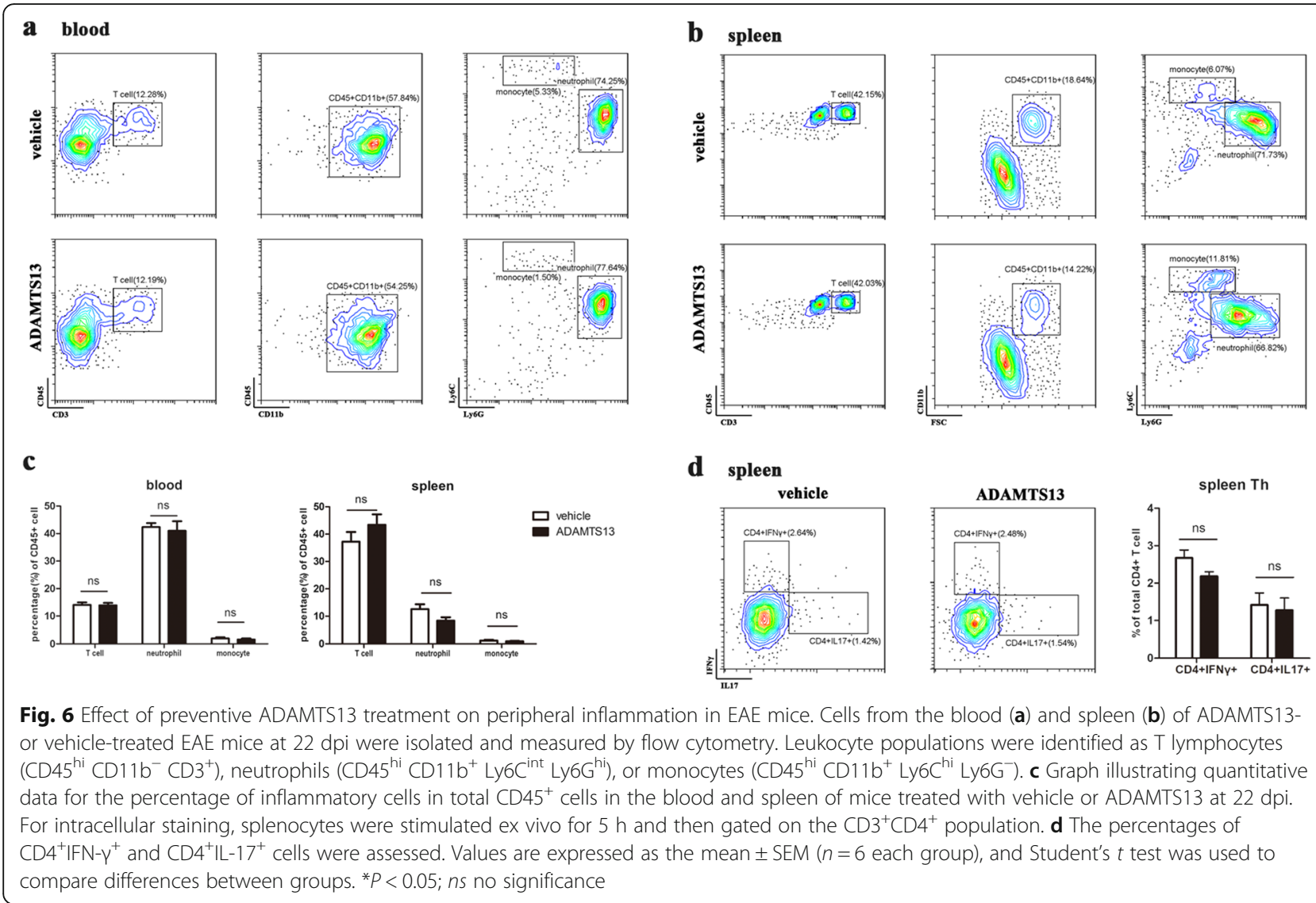

reported to play an essential role in EAE pathology by regulating the differentiation and proliferation of $\mathrm{CD} 4 \mathrm{~T}$ cells $[45,46]$. However, further studies may be required to elucidate whether the protective effect of ADAMTS13 in EAE mice partly depends on the role of activated platelets.

Dysfunction of the blood-brain barrier (BBB) and invasion of activated leukocytes into the CNS are essential for the development of multiple sclerosis and EAE [47]. Moreover, recent studies have confirmed the effect of the ADAMTS13-VWF axis on BBB permeability in models of stroke, traumatic brain injury, and cerebral malaria [13, 16, 25, 48]. For example, studies have reported that intraventricular administration of VWF leads to increased BBB permeability and that ADAMTS13 blocked BBB opening in both ischemic and hemorrhagic stroke mice $[13,16]$. Furthermore, compared with WT controls, VWF knockout mice tend to exhibit obviously alleviated BBB permeability in a model of cerebral malaria, hypoxia, and seizures $[48,49]$. In our study, the increased BSCB permeability detected in EAE mice was significantly attenuated by ADAMTS13 administration, and this effect might be involved in the action of ADAMTS13 in the mouse model of MS. In contrast, VWF knockout mice were reported to have increased susceptibility to EAE and worse BBB disruption [50]. The possible explanation for these paradoxical results may be that the absence of VWF led to a defect in Weibel-Palade body formation [51], which stores and secretes both pro-inflammatory and anti-inflammatory factors, thus making it difficult to interpret data. The balance between various factors can be disrupted by VWF knockout, resulting in increased BBB permeability. The VWF antibody may be an excellent tool for further investigating VWF function in EAE mice.

Because preventive ADAMTS13 administration before EAE onset is not feasible in the clinical setting, we further confirmed the protective effect of therapeutic administration of ADAMTS13 in EAE mice. However, there are several limitations in our study. First, given that it is technically difficult for us to inject drugs into the tail vein once a day for 2 weeks, ADAMTS13 was administered intracerebroventricularly in our study, which is not feasible in the clinical setting. Second, we found that the percentage of leukocyte subsets in the peripheral immune response and Th1/Th17 cell subsets in the spleen were not affected by ADAMTS13 administration into the lateral ventricle. However, our finding could not completely 

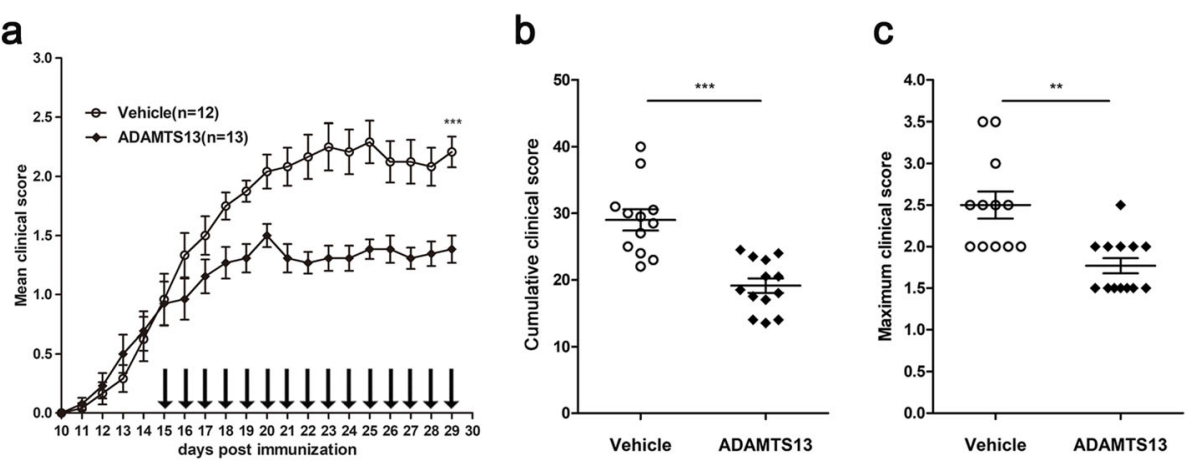

\section{d}
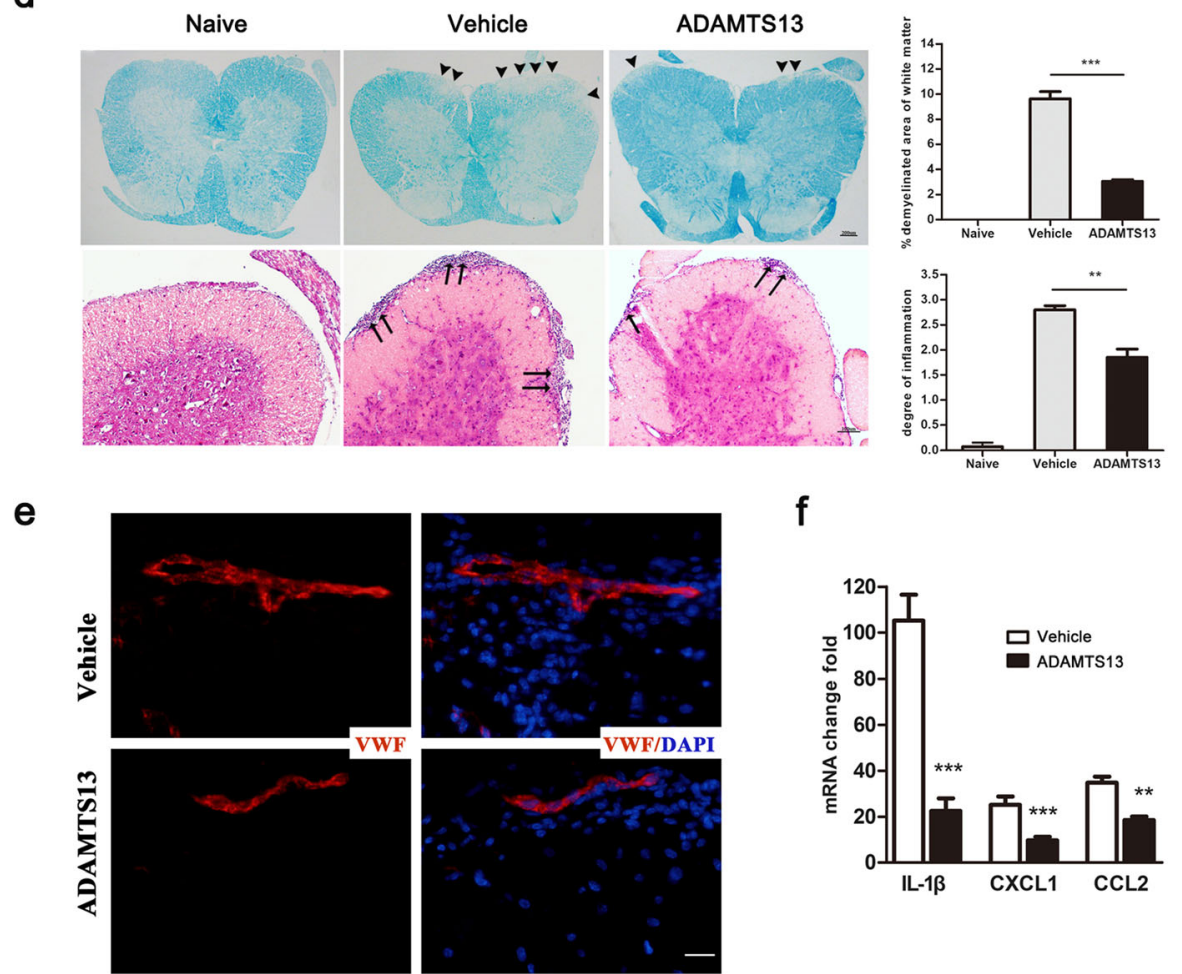

f

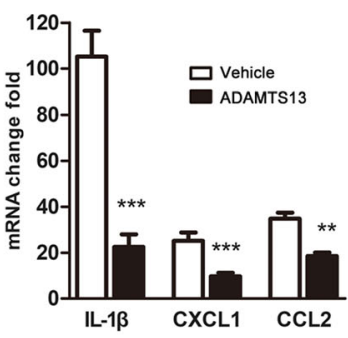

Fig. 7 Therapeutic treatment with ADAMTS13 reduces neurological deficits in established EAE mice. Fifty micrograms of ADAMTS13 or vehicle was injected into the lateral ventricle of EAE mice every day from $15 \mathrm{dpi}$ until $29 \mathrm{dpi}$, and clinical scores were recorded daily. a The daily mean clinical score is shown, and the mean clinical scores at 29 dpi were compared between vehicle and ADAMTS13 group $\left.{ }^{* * *} P<0.001\right)$. $\mathbf{b}$ Cumulative clinical score was summed by adding daily clinical scores from 15 dpi to 29 dpi. c Maximum clinical scores of EAE mice were compared between groups. Statistical significance was determined by the Mann-Whitney $U$ test for clinical scores. $\mathbf{d}$ Lumbar spinal cord sections of EAE mice at 30 dpi were subjected to LFB (upper panels) and HE (lower panels) staining for assessment of demyelination and inflammation, respectively. The arrowhead shows demyelinating lesions, and the arrow shows the area of inflammation. Scale bars represent $100 \mu \mathrm{m}$ and $200 \mu \mathrm{m}$. The percent of white matter demyelination and the level of inflammatory cell infiltration of the spinal cord were compared between ADAMTS13- and vehicle-treated EAE mice by Student's $t$ test $(n=4)$. e Tissue sections of spinal sections from EAE mice at 30 dpi were stained with antibodies against VWF (red) and DAPI (blue, nucleus). Bars, $20 \mu \mathrm{m}$. f Quantitative RT-PCR analysis of IL-1 $\beta$, CXCL1, and CCL2 mRNA levels in the spinal cords of ADAMTS13- and vehicle-treated EAE mice at $30 \mathrm{dpi}$. Data represent fold changes compared to the spinal cords of naïve mice $(n=6)$. Values are expressed as the mean \pm SEM. ${ }^{*} P<0.05 ;{ }^{*} P<0.01 ; * * * 0.001$

exclude a potential effect of ADAMTS13 on the peripheral immune response in EAE mice. Third, although decreased ADAMTS13 activity has been characterized, the role of the ADAMTS13-VWF axis in EAE remains to be determined. Therefore, further work including ADAMTS13 knockout will be required to fully elucidate the role of ADAMTS13 in the pathogenesis of EAE. Finally, it remains to be investigated whether processes other than the VWF pathway might be influenced by ADAMTS13. 


\section{Conclusions}

ADAMTS13 activity is suppressed in EAE mice. Furthermore, for the first time, this study shows that ADAMTS13 inhibits the CNS immune response, prevents $\mathrm{BSCB}$ disruption, and ameliorates demyelination and disease course in EAE mice. Therefore, our study suggests that ADAMTS13 may represent a potential therapeutic strategy for MS patients.

\section{Supplementary information}

Supplementary information accompanies this paper at https://doi.org/10. 1186/s12974-020-1713-z.

Additional file 1. Effect of preventive ADAMTS13 treatment on mean

clinical score.

\section{Abbreviations}

BSCB: Blood-spinal cord barriers; CNS: Central nervous system; EAE: Experimental autoimmune encephalomyelitis; ELISA: Enzyme-linked immunosorbent assay; Iba1: Ionized calciumbinding adapter molecule 1; MS: Multiple sclerosis; PBS: Phosphate-buffered saline; WWF: Von Willebrand factor

\section{Acknowledgments}

Not applicable.

\section{Authors' contributions}

$\mathrm{KLL}, \mathrm{BQZ}$, and $\mathrm{XJZ}$ designed the research. $\mathrm{KLL}, \mathrm{LL}, \mathrm{XFX}$, and $\mathrm{FZ}$ performed the experiments. JSD, XT, and XZW analyzed all the data. KLL, LL, and XJZ contributed to the manuscript. YWZ supervised and oversaw the research process. All authors read and approved the final manuscript.

\section{Funding}

This work was supported by grants from Foundation of Shanghai Municipal Commission of Health and Family Planning (2018YQ13) to XiaoJie Zhang, the National Natural Science Foundation of China (31771185) to Yuwu Zhao, and the Shanghai Municipal Science and Technology Major Project (2018SHZDZX01) to Bing-Qiao Zhao.

\section{Availability of data and materials}

The datasets used and/or analyzed during the current study are available from the corresponding author on reasonable request.

\section{Ethics approval and consent to participate}

All animal experiments were carried out according to the guidelines published by Shanghai Jiao Tong University Affiliated Sixth People's Hospital Animal Ethics committee.

\section{Consent for publication}

Not applicable.

\section{Competing interests}

The authors declare that they have no competing interests.

\section{Author details}

${ }^{1}$ Department of Neurology, Shanghai Jiao Tong University Affiliated Sixth People's Hospital, No. 600, Yishan Road, Xuhui District, Shanghai, China. ${ }^{2}$ Department of Translational Neuroscience, Jing'an District Centre Hospital of Shanghai, State Key Laboratory of Medical Neurobiology and MOE Frontiers Center for Brain Science, Institutes of Brain Science, Fudan University, Shanghai, China.
Received: 27 September 2019 Accepted: 13 January 2020

Published online: 19 February 2020

\section{References}

1. Ffrench-Constant C. Pathogenesis of multiple sclerosis. Lancet. 1994;343: $271-5$.

2. Gay FW, Drye TJ, Dick GW, Esiri MM. The application of multifactorial cluster analysis in the staging of plaques in early multiple sclerosis. Identification and characterization of the primary demyelinating lesion. Brain. 1997;120: 1461-83.

3. Goverman J. Autoimmune T cell responses in the central nervous system. Nat Rev Immunol. 2009;9:393-407.

4. Han MH, Hwang SI, Roy DB, Lundgren DH, Price JV, Ousman SS, Fernald GH, Gerlitz B, Robinson WH, Baranzini SE, Grinnell BW, Raine CS, Sobel RA, Han DK, Steinman L. Proteomic analysis of active multiple sclerosis lesions reveals therapeutic targets. Nature. 2008;451:1076-81.

5. Davalos D, Ryu JK, Merlini M, Baeten KM, Le Moan N, Petersen MA, Deerinck TJ, Smirnoff DS, Bedard C, Hakozaki H, Gonias Murray S, Ling JB, Lassmann $H$, Degen JL, Ellisman MH, Akassoglou K. Fibrinogen-induced perivascular microglial clustering is required for the development of axonal damage in neuroinflammation. Nat Commun. 2012;3:1227.

6. Ryu JK, Petersen MA, Murray SG, Baeten KM, Meyer-Franke A, Chan JP, Vagena E, Bedard C, Machado MR, Rios Coronado PE, Prod'homme T, Charo IF, Lassmann H, Degen JL, Zamvil SS, Akassoglou K. Blood coagulation protein fibrinogen promotes autoimmunity and demyelination via chemokine release and antigen presentation. Nat Commun. 2015:6:8164.

7. Gobel K, Pankratz S, Asaridou CM, Herrmann AM, Bittner S, Merker M, Ruck T, Glumm S, Langhauser F, Kraft P, Krug TF, Breuer J, Herold M, Gross CC, Beckmann D, Korb-Pap A, Schuhmann MK, Kuerten S, Mitroulis I, Ruppert C, Nolte MW, Panousis C, Klotz L, Kehrel B, Korn T, Langer HF, Pap T, Nieswandt B, Wiendl H, Chavakis T, Kleinschnitz C, Meuth SG. Blood coagulation factor XII drives adaptive immunity during neuroinflammation via CD87-mediated modulation of dendritic cells. Nat Commun. 2016;7:11626.

8. Stolz L, Derouiche A, Devraj K, Weber F, Brunkhorst R, Foerch C. Anticoagulation with warfarin and rivaroxaban ameliorates experimental autoimmune encephalomyelitis. J Neuroinflammation. 2017;14:152.

9. Ziliotto N, Bernardi F, Jakimovski D, Baroni M, Marchetti G, Bergsland N, Ramasamy DP, Weinstock-Guttman B, Schweser F, Zamboni P, Ramanathan M, Zivadinov R. Hemostasis biomarkers in multiple sclerosis. Eur J Neurol. 2018;25:1169-76.

10. Fujikawa K, Suzuki H, McMullen B, Chung D. Purification of human von Willebrand factor-cleaving protease and its identification as a new member of the metalloproteinase family. Blood. 2001;98:1662-6.

11. Sadler JE. A new name in thrombosis, ADAMTS13. Proc Natl Acad Sci U S A 2002;99:11552-4.

12. Zhao BQ, Chauhan AK, Canault M, Patten IS, Yang JJ, Dockal M, Scheiflinger F, Wagner DD. von Willebrand factor-cleaving protease ADAMTS13 reduces ischemic brain injury in experimental stroke. Blood. 2009:114:3329-34.

13. Cai P, Luo H, Xu H, Zhu X, Xu W, Dai Y, Xiao J, Cao Y, Zhao Y, Zhao BQ, Fan W. Recombinant ADAMTS 13 attenuates brain injury after Intracerebral hemorrhage. Stroke. 2015;46:2647-53.

14. Fujioka M, Hayakawa K, Mishima K, Kunizawa A, Irie K, Higuchi S, Nakano T, Muroi C, Fukushima H, Sugimoto M, Banno F, Kokame K, Miyata T, Fujiwara M, Okuchi K, Nishio K. ADAMTS13 gene deletion aggravates ischemic brain damage: a possible neuroprotective role of ADAMTS13 by ameliorating postischemic hypoperfusion. Blood. 2010;115:1650-3

15. Khan MM, Motto DG, Lentz SR, Chauhan AK. ADAMTS13 reduces WFmediated acute inflammation following focal cerebral ischemia in mice. J Thromb Haemost. 2012:10:1665-71.

16. Wang L, Fan W, Cai P, Fan M, Zhu X, Dai Y, Sun C, Cheng Y, Zheng P, Zhao $B Q$. Recombinant ADAMTS13 reduces tissue plasminogen activator-induced hemorrhage after stroke in mice. Ann Neurol. 2013;73:189-98.

17. Stromnes IM, Goverman JM. Active induction of experimental allergic encephalomyelitis. Nat Protoc. 2006;1:1810-9.

18. Cao Y, Xu H, Zhu Y, Shi MJ, Wei L, Zhang J, Cheng S, Shi Y, Tong H, Kang L, Lu L, Luo H, Yang X, Bai X, Wang R, Ma Y, Wang Y, Wang Z, Zhong K, Zhao $B Q$, Fan W. ADAMTS13 maintains cerebrovascular integrity to ameliorate Alzheimer-like pathology. PLoS Biol. 2019;17:e3000313.

19. Xu H, Cao Y, Yang X, Cai P, Kang L, Zhu X, Luo H, Lu L, Wei L, Bai X, Zhu Y, Zhao BQ, Fan W. ADAMTS13 controls vascular remodeling by modifying WWF reactivity during stroke recovery. Blood. 2017;130:11-22. 
20. Jin SY, Tohyama J, Bauer RC, Cao NN, Rader DJ, Zheng XL. Genetic ablation of Adamts13 gene dramatically accelerates the formation of early atherosclerosis in a murine model. Arterioscler Thromb Vasc Biol. 2012;32: 1817-23.

21. De Meyer SF, Savchenko AS, Haas MS, Schatzberg D, Carroll MC, Schiviz A, Dietrich $B$, Rottensteiner $H$, Scheiflinger $F$, Wagner DD. Protective antiinflammatory effect of ADAMTS13 on myocardial ischemia/reperfusion injury in mice. Blood. 2012;120:5217-23.

22. Borjini N, Fernandez M, Giardino L, Calza L. Cytokine and chemokine alterations in tissue, CSF, and plasma in early presymptomatic phase of experimental allergic encephalomyelitis (EAE), in a rat model of multiple sclerosis. J Neuroinflammation. 2016;13:291.

23. Warnick RE, Fike JR, Chan PH, Anderson DK, Ross GY, Gutin PH. Measurement of vascular permeability in spinal cord using Evans blue spectrophotometry and correction for turbidity. J Neurosci Methods. 1995: 58:167-71.

24. Cheng Y, Sun L, Xie Z, Fan X, Cao Q, Han J, Zhu J, Jin T. Diversity of immune cell types in multiple sclerosis and its animal model: pathological and therapeutic implications. J Neurosci Res. 2017;95:1973-83.

25. Wu Y, Liu W, Zhou Y, Hilton T, Zhao Z, Liu W, Wang M, Yeon J, Houck K, Thiagarajan P, Zhang F, Shi FD, Wu X, Li M, Dong JF, Zhang J. von Willebrand factor enhances microvesicle-induced vascular leakage and coagulopathy in mice with traumatic brain injury. Blood. 2018;132:1075-84

26. Ono T, Mimuro J, Madoiwa S, Soejima K, Kashiwakura Y, Ishiwata A, Takano K, Ohmori T, Sakata Y. Severe secondary deficiency of von Willebrand factorcleaving protease (ADAMTS13) in patients with sepsis-induced disseminated intravascular coagulation: its correlation with development of renal failure. Blood. 2006;107:528-34.

27. Reiter RA, Varadi K, Turecek PL, Jilma B, Knobl P. Changes in ADAMTS13 (von-Willebrand-factor-cleaving protease) activity after induced release of von Willebrand factor during acute systemic inflammation. Thromb Haemost. 2005;93:554-8.

28. Vergouwen MD, Bakhtiari K, van Geloven N, Vermeulen M, Roos YB, Meijers JC. Reduced ADAMTS13 activity in delayed cerebral ischemia after aneurysmal subarachnoid hemorrhage. J Cereb Blood Flow Metab. 2009;29: 1734-41.

29. Reiter RA, Knobl P, Varadi K, Turecek PL. Changes in von Willebrand factorcleaving protease (ADAMTS13) activity after infusion of desmopressin. Blood. 2003;101:946-8.

30. Cao WJ, Niiya M, Zheng XW, Shang DZ, Zheng XL. Inflammatory cytokines inhibit ADAMTS13 synthesis in hepatic stellate cells and endothelial cells. Thromb Haemost. 2008;6:1233-5.

31. Bernardo A, Ball C, Nolasco L, Moake JF, Dong JF. Effects of inflammatory cytokines on the release and cleavage of the endothelial cell-derived ultralarge von Willebrand factor multimers under flow. Blood. 2004:104:100-6.

32. Orvain C, Augusto JF, Besson V, Marc G, Coppo P, Subra JF, Sayegh J. Thrombotic microangiopathy due to acquired ADAMTS13 deficiency in a patient receiving interferon-beta treatment for multiple sclerosis. Int Urol Nephrol. 2014;46:239-42.

33. Nishio H, Tsukamoto T, Matsubara T, Okada Y, Takahashi R, Yanagita M. Thrombotic microangiopathy caused by interferon beta-1b for multiple sclerosis: a case report. CEN Case Rep. 2016;5:179-83.

34. Larochelle C, Grand'maison F, Bernier GP, Latour M, Cailhier JF, Prat A. Thrombotic thrombocytopenic purpura-hemolytic uremic syndrome in relapsing-remitting multiple sclerosis patients on high-dose interferon beta. Mult Scler. 2014;20:1783-7.

35. Pierson ER, Wagner CA, Goverman JM. The contribution of neutrophils to CNS autoimmunity. Clin Immunol. 2018;189:23-8.

36. Mishra MK, Yong WW. Myeloid cells - targets of medication in multiple sclerosis. Nat Rev Neurol. 2016;12:539-51.

37. Zhu J, Yamane H, Paul WE. Differentiation of effector CD4 T cell populations (*). Annu Rev Immunol. 2010;28:445-89.

38. Schoenborn JR, Wilson CB. Regulation of interferon- $\gamma$ during innate and adaptive immune responses [M]; 2007. p. 41-101.

39. Dungan LS, McGuinness NC, Boon L, Lynch MA, Mills KH. Innate IFN- $\gamma$ promotes development of experimental autoimmune encephalomyelitis: a role for NK cells and M1 macrophages. Eur J Immunol. 2014;44:2903-17.

40. Ott M, Avendano-Guzman E, Ullrich E, Dreyer C, Strauss J, Harden M Schon M, Schon MP, Bernhardt G, Stadelmann C, Wegner C, Bruck W, Nessler S. Laquinimod, a prototypic quinoline-3-carboxamide and aryl hydrocarbon receptor agonist, utilizes a CD155-mediated natural killer/ dendritic cell interaction to suppress CNS autoimmunity. Neuroinflammation. 2019:16:49.

41. Liu Q, Sanai N, Jin WN, La Cava A, Van Kaer L, Shi FD. Neural stem cells sustain natural killer cells that dictate recovery from brain inflammation. Nat Neurosci. 2016;19:243-52.

42. Chauhan AK, Kisucka J, Brill A, Walsh MT, Scheiflinger F, Wagner DD. ADAMTS13: a new link between thrombosis and inflammation. J Exp Med. 2008;205:2065-74.

43. Gandhi C, Ahmad A, Wilson KM, Chauhan AK. ADAMTS13 modulates atherosclerotic plaque progression in mice via a WWF-dependent mechanism. J Thromb Haemost. 2014;12:255-60.

44. Gandhi C, Khan MM, Lentz SR, Chauhan AK. ADAMTS13 reduces vascular inflammation and the development of early atherosclerosis in mice. Blood. 2012;119:2385-91.

45. Starossom SC, Veremeyko T, Yung AW, Dukhinova M, Au C, Lau AY, Weiner $\mathrm{HL}$, Ponomarev ED. Platelets play differential role during the initiation and progression of autoimmune Neuroinflammation. Circ Res. 2015:117:779-92.

46. Langer HF, Choi EY, Zhou H, Schleicher R, Chung KJ, Tang Z, Gobel K, Bdeir K, Chatzigeorgiou A, Wong C, Bhatia S, Kruhlak MJ, Rose JW, Burns JB, Hill KE, Qu H, Zhang Y, Lehrmann E, Becker KG, Wang Y, Simon DI, Nieswandt B, Lambris JD, Li X, Meuth SG, Kubes P, Chavakis T. Platelets contribute to the pathogenesis of experimental autoimmune encephalomyelitis. Circ Res. 2012;110:1202-10

47. Minagar A, Alexander JS. Blood-brain barrier disruption in multiple sclerosis. Mult Scler. 2003:9:540-9.

48. O'Regan N, Gegenbauer K, O'Sullivan JM, Maleki S, Brophy TM, Dalton N, Chion A, Fallon PG, Grau GE, Budde U, Smith OP, Craig AG, Preston RJ, O'Donnell JS. A novel role for von Willebrand factor in the pathogenesis of experimental cerebral malaria. Blood. 2016;127:1192-201.

49. Suidan GL, Brill A, De Meyer SF, Voorhees JR, Cifuni SM, Cabral JE, Wagner DD. Endothelial Von Willebrand factor promotes blood-brain barrier flexibility and provides protection from hypoxia and seizures in mice. Arterioscler Thromb Vasc Biol. 2013:33:2112-20.

50. Noubade R, del Rio R, McElvany B, Zachary JF, Millward JM, Wagner DD, Offner $\mathrm{H}$, Blankenhorn EP, Teuscher C. von-Willebrand factor influences blood brain barrier permeability and brain inflammation in experimental allergic encephalomyelitis. Am J Pathol. 2008;173:892-900.

51. Denis CV, Andre P, Saffaripour S, Wagner DD. Defect in regulated secretion of P-selectin affects leukocyte recruitment in von Willebrand factor-deficient mice. Proc Natl Acad Sci U S A. 2001;98:4072-7.

\section{Publisher's Note}

Springer Nature remains neutral with regard to jurisdictional claims in published maps and institutional affiliations.

\section{Ready to submit your research? Choose BMC and benefit from:}

- fast, convenient online submission

- thorough peer review by experienced researchers in your field

- rapid publication on acceptance

- support for research data, including large and complex data types

- gold Open Access which fosters wider collaboration and increased citations

- maximum visibility for your research: over $100 \mathrm{M}$ website views per year

At BMC, research is always in progress.

Learn more biomedcentral.com/submissions 